\title{
POLA KONSUMSI AIR PADA PERUMAHAN TERATUR: STUDI KASUS KONSUMSI AIR DI PERUMAHAN GRIYA SERPONG TANGERANG SELATAN
}

\author{
WATER CONSUMPTION PATTERN IN A REGULAR HOUSING: \\ WATER CONSUMPTION CASE STUDY IN GRIYA SERPONG HOUSING \\ IN TANGERANG SELATAN
}

\author{
Alfrida E. Suoth ${ }^{1}$, Sri Unon Purwati² dan Yuriska Andiri ${ }^{3}$
}

Diterima tanggal 30 Juli 2018, Disetujui tanggal 8 September 2018

\begin{abstract}
ABSTRAK
Air merupakan salah satu sumber daya alam yang sangat dibutuhkan dalam kehidupan sehari-hari. Kekeliruan dalam memanfaatkan air dapat mengakibatkan krisis air. Pola Konsumsi dan Produksi Berkelanjutan disebut juga Sustainable Consumption and Production (SCP) merupakan salah satu bagian penting untuk mewujudkan pembangunan yang berkelanjutan terkait dengan sumber daya alam yang kita miliki yaitu air. Penelitian ini terkait efisiensi penggunaan air dalam rumah tangga, didata pola konsumsi air pada masyarakat perkotaan dan kebutuhan air perorangan pada perumahan kelas menengah ke bawah. Metode penelitian dilakukan menggunakan kuesioner dengan jumlah responden sebesar 100 responden dan penentuan menggunakan metode acak random. Lokasi penelitian di perumahan teratur Griya Serpong Kelurahan Kademangan, Kecamatan Setu, Tangerang Selatan. Perumahan ini tergolong perumahan teratur dengan tingkat ekonomi kelas menengah ke bawah. Limbah domestik berupa Grey water berasal dari air buangan dari kegiatan mandi, cuci pakaian, cuci peralatan makan/masak, cuci kendaraan dan siram tanaman, toilet, namun tidak termasuk air yang berasal dari WC merupakan fokus penelitian selain data ekonomi sosial. Hasil penelitian ini apabila dibandingkan dengan penduduk metropolitan sebagai acuan maka masih tergolong pengguna efektif air bersih dengan hasil perhitungan 135,7 liter/orang/hari karena angka ini masih lebih rendah dari konsumsi air yang ditetapkan SNI yaitu sebanyak 150 Liter/orang/hari. Pola konsumsi air penduduk Perumahan Griya Serpong 30\% digunakan untuk mandi, 20\% untuk cuci pakaian, 16\% untuk kegiatan dapur, $14 \%$ untuk cuci kendaraan, $10 \%$ untuk kegiatan toilet dan sisanya untuk menunjang aktifitas harian lainnya.
\end{abstract}

Kata Kunci: pola konsumsi air, gray water, kebutuhan air.

\begin{abstract}
Water is one of the natural resources that are essentially needed in everyday life. Mishandling in water management can cause a water crisis. The Sustainable Consumption and Production (SCP) is an important part in achieving sustainable development related to the water resources. This research is related to the efficiency of water use in households and the patterns of water consumption in urban communities and individual water needs in middle to lower class housing. The research method was carried out using a questionnaire with a total of 100 respondents and the determination using random method. The research location was undergone in a regular housing classified as lower middle class economy named Griya Serpong Kademangan Village, Setu District, South Tangerang. Domestic waste in the form of Grey water comes from wastewater from bathing, washing clothes, washing eating / cooking utensils, vehicle washing and plant flushing, toilets, but not including water from water closet (WC), is the research focus besides social economic data. The results of this study when compared to the metropolitan population as a reference, are still classified as effective users of clean water with the calculation of 135,7 liters / person / day because this figure is still lower than the water consumption set by SNI as much as 150 liters / person / day. The water consumption pattern of the 30\% Griya Serpong Housing is used for bathing, 20\% for clothes washing, $16 \%$ for kitchen activities, $14 \%$ for vehicle washing, $10 \%$ for toilet activities and the rest to support other daily activities.
\end{abstract}

Keyword: consumption behavior, gray water, water consumption.

\footnotetext{
${ }^{1,2}$ Fungsional Pedal pada Puslitbang Kualitas dan Laboratorium Lingkungan BLI-KLHK

3 Staf pada Puslitbang Kualitas dan Laboratorium Lingkungan BLI-KLHK
} 


\section{PENDAHULUAN}

Produksi dan Konsumsi Berkelanjutan (Sustainable Consumption and Production/ $S C P$ ) adalah salah satu sub-tema aksi mewujudkan Pembangunan Berkelanjutan yang telah dicanangkan sejak Deklarasi Rio tahun 1992, dan selanjutnya dikuatkan dengan Johannesburg Plan of Implementation tahun 2002. Konsep konsumsi dan produksi berkelanjutan berfokus pada serangkaian upaya pengurangan dampak negatif terhadap lingkungan sepanjang daur hidup produk atau jasa, yang terkait dengan kegiatan masyarakat dalam melakukan produksi dan konsumsi setiap hari. SCP dapat menjadi bagian penting dan memberikan solusi bagi aksi mitigasi dan adaptasi menghadapi Perubahan Iklim. Konsep Ekonomi Hijau harus mencakup esensi dari SCP dan harus merangkul berbagai pendekatan, seperti mengubah konsumsi dan produksi yang tidak berkelanjutan, bergaya hidup hijau, dan lain sebagainya. Ekonomi hijau harus diterjemahkan sebagai kebijakan inklusif yang bertujuan pada efisiensi sumber daya termasuk didalamnya adalah $\operatorname{air}^{(2)}$.

Perkembangan ekonomi dan peningkatan populasi dalam beberapa dekade terakhir telah menyebabkan peningkatan pesat konsumsi air tawar, yang dapat menghambat pembangunan masyarakat. Saat ini, sekitar sepertiga penduduk dunia terancam oleh kurangnya air tawar untuk memenuhi kebutuhan sehari-hari. Selain itu, peningkatan kelangkaan air di berbagai wilayah diperkirakan terjadi di masa depan karena berbagai faktor seperti pertumbuhan penduduk, pencemaran sumber daya yang ada, perubahan iklim, dan urbanisasi. Hampir tujuh miliar orang di seluruh dunia diprediksi menghadapi krisis air pada pertengahan abad ke-2 $1^{(19)}$

Sumber daya air merupakan sumber daya yang tidak terbaharukan mengharuskan manusia untuk bertindak bijak dalam pemakaiannya. Penggunaan air di dalam rumah tangga selama ini masih sangat sulit untuk dilakukan pengelolaan tetapi di sisi lain penggunaan air dalam rumah tangga adalah penyumbang terbesar terjadinya krisis air. Dampak konsumsi manusia pada sumber daya air global dapat dipetakan menggunakan jejak air. Konsep jejak air diusulkan dan didefinisikan sebagai "ukuran perampasan manusia terhadap sumber daya air tawar". Jejak air adalah indikator penggunaan air di mana dimasukkan konsumsi air dan polusi; mereka juga dapat diterapkan untuk memperluas sistem evaluasi sumber daya air dan menyediakan informasi pemanfaatan air untuk pengambilan keputusan ${ }^{(19)}$.

Krisis lingkungan hidup yang terjadi saat ini, salah satu penyebabnya adalah konsumsi SDA yang berlebihan, pola konsumsi yang tidak berkelanjutan dan tidak ramah lingkungan (hijau), dan penggunaan air yang berlebihan, berujung pada krisis kekurangan air. Terkait hal tersebut maka penting untuk mengetahui pola konsumsi air dalam rumah tangga untuk masyarakat perkotaan melalui inventarisasi sumber-sumber air limbah domestik (greywater) serta pemakaian air rata-rata per hari untuk kegiatan rumah tangga.

Pemilihan daerah penelitian di Tangerang Selatan karena Kota Tangerang Selatan merupakan kota terbesar kedua di Provinsi Banten setelah Kota Tangerang serta terbesar kelima di kawasan Jabodetabek setelah Jakarta, Bekasi, Tangerang, dan Depok. Wilayah 
Tabel 1. Jumlah Penduduk Kota Tangerang Selatan

\begin{tabular}{lccccccc}
\hline \multirow{2}{*}{ Kecamaatan } & \multicolumn{9}{c}{ Jumlah Penduduk (Jiwa) } \\
\cline { 2 - 8 } & 2010 & 2011 & 2012 & 2013 & 2014 & 2015 & 2016 \\
\hline Setu & 66667 & 69391 & 72170 & 75002 & 77881 & 80811 & 83777 \\
Serpong & 138177 & 144378 & 150736 & 157252 & 163915 & 170731 & 177677 \\
Pamulang & 287955 & 296915 & 305909 & 314931 & 323957 & 332984 & 341967 \\
Ciputat & 193369 & 199807 & 206293 & 212824 & 219384 & 225974 & 232559 \\
Ciputat Timur & 179792 & 184391 & 188957 & 193484 & 197960 & 202386 & 206729 \\
Pondok Aren & 305073 & 316988 & 329103 & 341416 & 353904 & 366568 & 379354 \\
Serpong Utara & 127471 & 134232 & 141237 & 148494 & 155998 & 163755 & 171749 \\
Kota Tangerang Selatan & 1298504 & 1346102 & 1394405 & 1443403 & 1492999 & 1543209 & 1593812 \\
\hline
\end{tabular}

Sumber : Data Badan Pusat Statistik Kota Tangerang, 13 Maret 2018

Kota Tangerang Selatan merupakan hasil pemekaran dari Kabupaten Tangerang. Jumlah penduduk Kota Tangerang Selatan lebih dari 1 juta jiwa termasuk dalam kelompok Kota Metropolitan. Peningkatan jumlah penduduk Kota Tangerang Selatan dari tahun 2010-2016 tertera pada Tabel 1 .

Kebutuhan air per jiwa per hari menurut SNI 19-6728.1-2002 tentang Penyusunan Neraca Sumber Daya tercantum $150 \mathrm{~L} / \mathrm{jiwa} /$ hari pada kota berpenduduk 1 juta jiwa demikian juga berdasarkan acuan dari Departemen Kesehatan menyebutkan kebutuhan air bersih per jiwa perhari adalah 150 Liter. Mengacu pada SNI tersebut maka standar yang dipakai untuk kebutuhan air di Kota Tangerang Selatan 150 liter air.

Tujuan penelitian ini adalah untuk mendapatkan paket data dan informasi pola konsumsi air dalam rumah tangga masyarakat perumahan perkotaan kelas menengah ke bawah yang berlokasi di Kelurahan Kademangan, Kecamatan Setu, Tangerang Selatan, tepatnya di Perumahan Griya Serpong.

\section{METODOLOGI}

Penelitian ini termasuk penelitian deskriptif yang memiliki tahapan pelaksanaan penelitian seperti tertera pada Gambar 1.

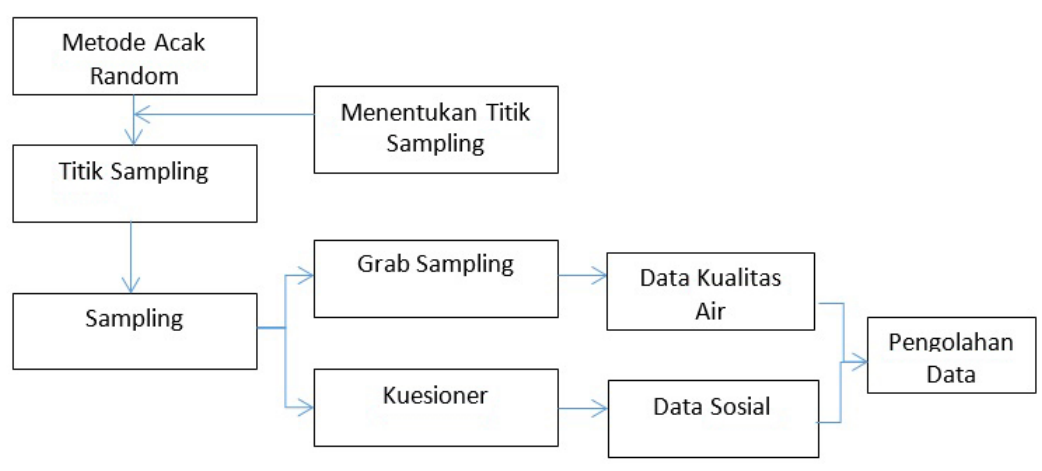

Gambar 1: Alur pikir logis penelitian 
Titik sampling dalam penelitian ini adalah rumah warga Perumahan Griya Serpong yang menjadi target penelitian. Titik sampling ditentukan menggunakan metode acak random. Sampling yang dilakukan ditujukan untuk dua (2) macam data yaitu data kualitas gray water parameter kimia-fisika dan data sosial. Data kualitas gray water diperoleh melalui grab sampling dan data sosial diperoleh melalui kuesioner. Perhitungan pola pemakaian air didasarkan pada konversi pemakaian air tiap aktifitas. Uji coba dilakukan terhadap kebutuhan jumlah air yang diperlukan per kegiatan yang selanjutnya ditetapkan sebagai volume konversi. Volume pemakaian air dijumlahkan setelah di konversi ke volume yang di tetapkan. Detail dari pelaksanaan penelitian seperti diuraikan dibawah ini.

\section{a. Lokasi Penelitian}

Lokasi penelitian di Perumahan Griya Serpong di Kelurahan Kademangan, Kecamatan Setu, Kota Tangerang Selatan. Perumahan ini memiliki 375 KK (kepala keluarga) yang tergabung dalam RW 06 dan dibagi dalam 5 RT. Kecamatan Setu adalah 1 dari 7 kecamatan yang berada di bawah Kota Tangerang Selatan dan terdiri dari 1 kelurahan dan 5 desa ${ }^{(9)}$, dengan jumlah 195 RT dan 40 RW. Peta lokasi penelitian dapat dilihat di gambar 2 .

Sumber data kependudukan berasal dari Sensus Penduduk dan Survei kependudukan yang dilakukan oleh BPS dan hasil Registrasi Penduduk jumlah penduduk di Kecamatan Setu adalah 72.727 orang dengan jumlah rumah tangga 18.7897 rumah tangga dengan luas wilayah $14,80 \mathrm{~km}^{2}{ }^{(9)}$. Pengambilan data kuesioner dilakukan terhadap 100 responden yang terbagi di 5 RT yang ada di perumahan Griya Serpong. . Teknik pengambilan sampel penelitian dilakukan secara acak sederhana dengan mengacu pada pendekatan rumus Slovin (Azh \& Suhartini, 2016), pendekatan ini dinyatakan dengan rumus sebagai berikut: $n=N /\left(1+\mathrm{N} . \mathrm{E}^{2}\right)$

Di mana, $\mathrm{n}=$ jumlah sampel; $\mathrm{N}=$ jumlah populasi; $\mathrm{E}=$ batas kesalahan yang ditoleransi dengan jumlah populasi 72.727 dengan batas kesalahan yang ditoleransi sebesar $10 \%$ maka jumlah sampel minimal adalah sebesar 100 responden.

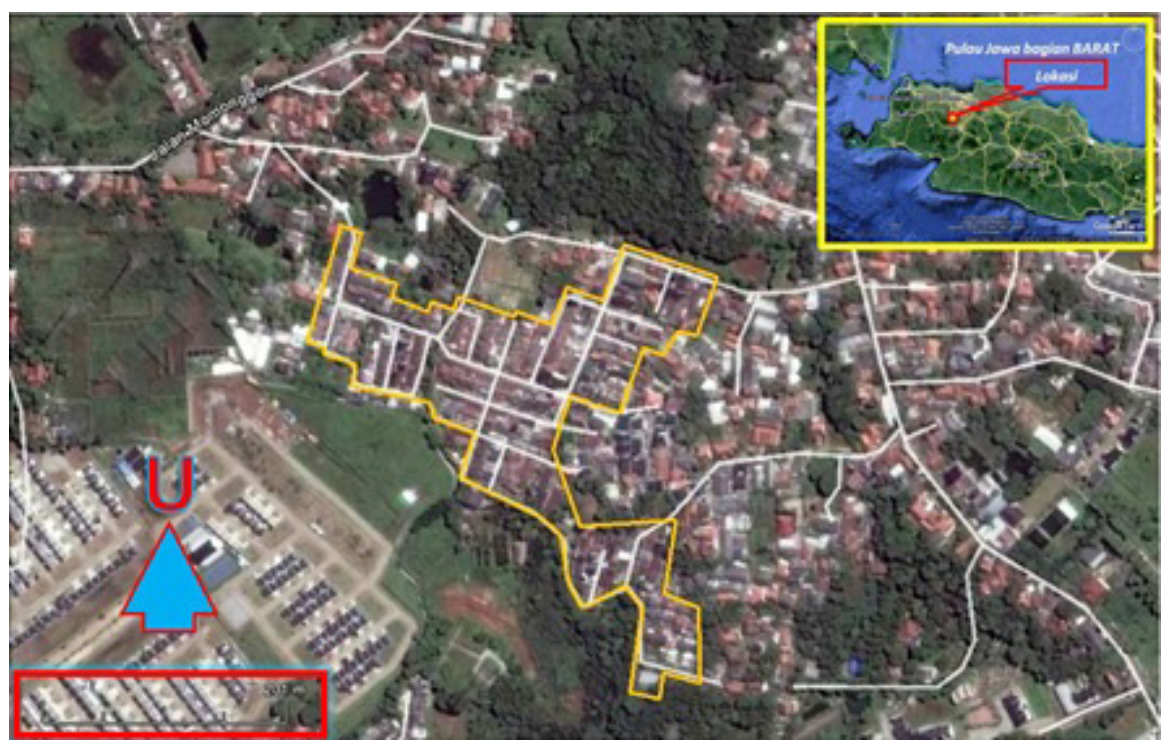

Gambar 2: Peta lokasi penelitian di Perumahan Griya Serpong Kelurahan Kademangan Kecamatan Setu Kota tangerang Selatan 


\section{b. Bahan dan Alat}

Bahan yang digunakan dalam penyusunan variabel penelitian ini adalah pertanyaan yang harus diisi atau dijawab oleh seluruh responden. Alat ukur yang digunakan untuk mengukur fenomena atau variabel penelitian adalah kuesioner.

Kuesioner (lihat lampiran) ditujukan untuk perumahan perkotaan kelas menengah ke bawah yang ada di Kota Tangerang Selatan tepatnya di kelurahan Kademangan, Kecamatan Setu yaitu Perumahan Griya Serpong. Kuesioner diberikan pada 100 responden. Pengumpulan data primer kuesioner dari tanggal $7 \mathrm{~s} / \mathrm{d}$ 31 Oktober 2016. Contoh diambil secara komposit, dengan menggabungkan contoh (volume sama) yang diambil pada pagi hari pukul 09.00 dan sore pukul 15.00.

\section{c. Analisis Data}

Analisis data pengambilan data primer meliputi langkah kegiatan sebagai berikut :

a. Tahap awal penelitian tahun 2016 adalah melakukan pengambilan data primer dengan menggunakan kuesioner. Kuesioner berisi inventarisasi semua kegiatan yang berhubungan dengan penggunaan air dalam rumah tangga.

b. Kuesioner/wawancara pada 100 rumah yang ada di perumahan Griya Serpong. Pemilihan rumah berdasarkan metode acak dan yang disurvei adalah rumah yang peruntukannya untuk rumah tangga (kost tidak termasuk).

c. Kuesioner yang digunakan dalam pengambilan data primer mempunyai 3 variabel dengan 27 instrumen.

d. Data primer yang terkumpul diinput dan dilakukan uji validitas, realibilitas dengan sistim komputer untuk memastikan semua data yang diperoleh melalui kuesioner adalah signifikan dan dapat dipercaya.

e. Pengolahan data dan analisa data menggunakan SPSS for windows versi 19.

Metode bersifat arbitrary digunakan untuk memperoleh data pada tabel 2 terkait pemakaian volume air yang dikonversi berdasarkan volume air alat ukur serupa gayung karena keterbatasan alat ukur yang tersedia. Data yang diperoleh merupakan dasar untuk perhitungan data pada tabel 4 terkait data pemakaian air per orang per hari di Perumahan Griya Serpong. Beberapa literatur menyebutkan bahwa perhitungan dilakukan dengan perkiraan, seperti pada SNI 03-70652005 tentang Tata Cara Perencanaan Sistem Plambing.

Tabel 2. Konversi volume air yang digunakan

\begin{tabular}{lc}
\hline \multicolumn{1}{c}{ Kegiatan } & $\begin{array}{c}\text { Volume air yang } \\
\text { dikonversikan tiap } \\
\text { kegiatan (Liter) }\end{array}$ \\
\hline Sikat gigi & 1 \\
Cuci pakaian (manual) & 100 \\
Cuci Pakaian (mesin) & 60 \\
Cuci Piring & 30 \\
Mandi & 20 \\
Kegiatan toilet & 5 \\
Bersih rumah & 16 \\
Siram tanaman & 20 \\
Cuci kendaraan (motor) & 15 \\
Air minum & 1,4 \\
\hline
\end{tabular}

\section{HASIL DAN PEMBAHASAN}

Kuesioner dilakukan terhadap 100 responden yang menyebar di 5 RT pada Perumahan Griya Serpong. Pekerjaan dari responden adalah pegawai swasta, guru, wirausaha dan ibu rumah tangga. Dengan jumlah variable 
4 dan jumlah instrument 37 serta hasil uji reabilitas data adalah signifikan.

Kesediaan masyarakat berpartisipasi dalam mengolah grey water menunjukkan tingkat yang baik. Terbukti dari data pendapat Masyarakat daerah penelitian yang setuju dalam penerapan pengolahan kembali grey water yaitu dari tingkat sedang sampai baik lihat Tabel 3.

Data pendapatan rumah tangga di daerah penelitian tergolong ekonomi rendah dan berada pada distribusi rendah. Memiliki pengetahuan tentang limbah pada tingkat frekuensi sedang dan mayoritas tidak memiliki pendapatan tambahan dengan kebutuhan air minum satu minggu sebanyak 2 galon. Sumber air yang digunakan oleh responden sebanyak $68 \%$ berasal dari PDAM. Responden yang bersedia berpartisipasi dalam pengelolaan air limbah grey water $87 \%$.
Hasil penelitian untuk perumahan kelas menengah ke bawah diperoleh perhitungan jumlah air yang dikonsumsi perorangan adalah 130,1 liter/hari meliputi kebutuhan air untuk mandi, minum, cuci pakaian, cuci peralatan makan/dapur, kebersihan rumah, siram tanaman dan mencuci kendaraan seperti di tunjukkan dalam Tabel 4 .

Tabel 4. Data pemakaian air per orang/hari di Perumahan Griya Serpong

\begin{tabular}{lc}
\hline \multicolumn{1}{c}{ Keperluan } & $\begin{array}{c}\text { Konsumsi Air } \\
\text { (liter) }\end{array}$ \\
\hline Sikat gigi & 2,2 \\
Cuci pakaian & 26,9 \\
Cuci piring, masak & 21,5 \\
mandi & 39,1 \\
Air minum & 1,9 \\
Membersihkan rumah & 5,5 \\
Siram tanaman & 3,7 \\
Kegiatan toilet & 13 \\
Cuci kendaraan & 16,3 \\
Total & 130,1 \\
\hline
\end{tabular}

Tabel 3. Hasil pengolahan data dalam kuesioner

\begin{tabular}{|c|c|c|c|}
\hline No. & Variabel & Sub variabe I & $\begin{array}{c}\text { Frekuensi } \\
\text { Terbes ar } \\
(\%)\end{array}$ \\
\hline 1 & Pekerjaan kepala Rumah Tangga & Pegawai swasta & 61 \\
\hline 2 & Luas bangunan rumah & $> \pm 45 \mathrm{~m} 2$ & 63 \\
\hline 3 & Luas tanah dari rumah & $70-100 \mathrm{~m} 2$ & 46 \\
\hline 4 & Penghasilan dalam RT & $3-5 \mathrm{jt}$ & 48 \\
\hline 5 & Pekerjaan tambahan & $\begin{array}{l}\text { Tidak mempunyai } \\
\text { pekerjaan tambahan. }\end{array}$ & 80 \\
\hline 6 & Pekerjaan istri & Ibu Rumah Tangga & 67 \\
\hline 7 & Sumber air untuk Rumah Tangga & PDAM & 68 \\
\hline 8 & $\begin{array}{l}\text { Memakai torn untuk menampung } \\
\text { air }\end{array}$ & Ya & 58 \\
\hline 9 & $\begin{array}{l}\text { Kebutuhan minum dalam } \\
\text { seminggu }\end{array}$ & 2 galon & 47 \\
\hline 10 & Alat mandi yang digunakan & gayung & 83 \\
\hline 11 & Jumlah toilet yang ada di rumah & 1 & 78 \\
\hline 12 & Pengetahuan ttg Air limbah & mengetahui & 52 \\
\hline 13 & $\begin{array}{l}\text { Setuju penerapan recycle air utk } \\
\text { dimanfaatkan kembaki utk siram } \\
\text { air. }\end{array}$ & setuju & 49 \\
\hline 14 & $\begin{array}{l}\text { Setuju mengolah kembali Gray } \\
\text { Water }\end{array}$ & setuju & 77 \\
\hline 15 & $\begin{array}{l}\text { Setuju penghematan air secara } \\
\text { umum }\end{array}$ & setuju & 70 \\
\hline 16 & $\begin{array}{l}\text { Bersedia dalam partisipasi olah } \\
\text { Gray Water }\end{array}$ & bersedia & 87 \\
\hline
\end{tabular}


Tabel 5. Standar kebutuhan air rumah tangga berdasarkan jenis kota dan jumlah penduduk

\begin{tabular}{ccc}
\hline Jumlah Penduduk & Jenis Kota & Jumlah Kebutuhan Air (Liter/orang/hari) \\
\hline$>\quad 2.000 .000$ & Metropolitan & $>210$ \\
$1.000 .000-2.000 .000$ & Metropolitan & $150-210$ \\
$500.000-1.000 .000$ & Besar & $120-150$ \\
$100.000-5000.000$ & Besar & $100-150$ \\
$20.000-100.000$ & Sedang & $90-100$ \\
$3.000-20.000$ & Kecil & $60-100$ \\
\hline
\end{tabular}

Sumber: (Pedoman konstruksi dan bangunan, Dep PU dalam direktorat Pengairan dan Irigasi Bapenas, $2006^{(12)}$

Hasil penelitian menunjukkan bahwa kebutuhan air rata-rata perorangan di Perumahan Griya jumlahnya 130,1 liter belum termasuk air untuk wudhu, jumlah ini masih di bawah jumlah air berdasarkan survei Ditjen Cipta Karya atau dengan kata lain masih hemat dibandingkan dengan hasil survey tahun 2006 sebanyak 144 Litter/hari (7). Penelitian ini dilakukan mengingat pola konsumsi air bersih masyarakat perkotaan berubah dan dipengaruhi faktor :

1. Ukuran keluarga

2. Pendapatan perkapita

3. Ukuran kota

4. Kota asal penduduk

5. Tipe meteran

6. Pendidikan responden

7. Kepadatan ruang
Berdasarkan literatur salah satu penelitian mengasumsikan rata-rata kebutuhan air wudhu untuk kran manual $1.132 \mathrm{~mL}$ atau 1,132 liter (12). Maka untuk 5 kali wudhu dalam sehari dibutuhkan 5,56 liter. Sehingga kebutuhan air rata-rata perorangan dengan menambahakan kebutuhan wudhu menjadi 130,1 liter $+5,56$ liter $=135,7$ liter. Untuk wudhu menggunakan kran air otomatis membutuhkan volume air rata-rata $600 \mathrm{~mL}$ atau 0,6 liter yaitu hampir 1/10 lebih sedikit dari jumlah air rata-rata menggunakan kran air manual.

Kota Tangerang Selatan mempunyai penduduk 1.405.170 orang, berdasarkan tabel 5 menurut jumlah penduduk di kategorikan ke dalam kota metropolitan dengan jumlah penduduk berkisar $1.000 .000-2.000 .000$. dengan jumlah kebutuhan air $150-210$ liter/orang/ hari ${ }^{(12)}$.

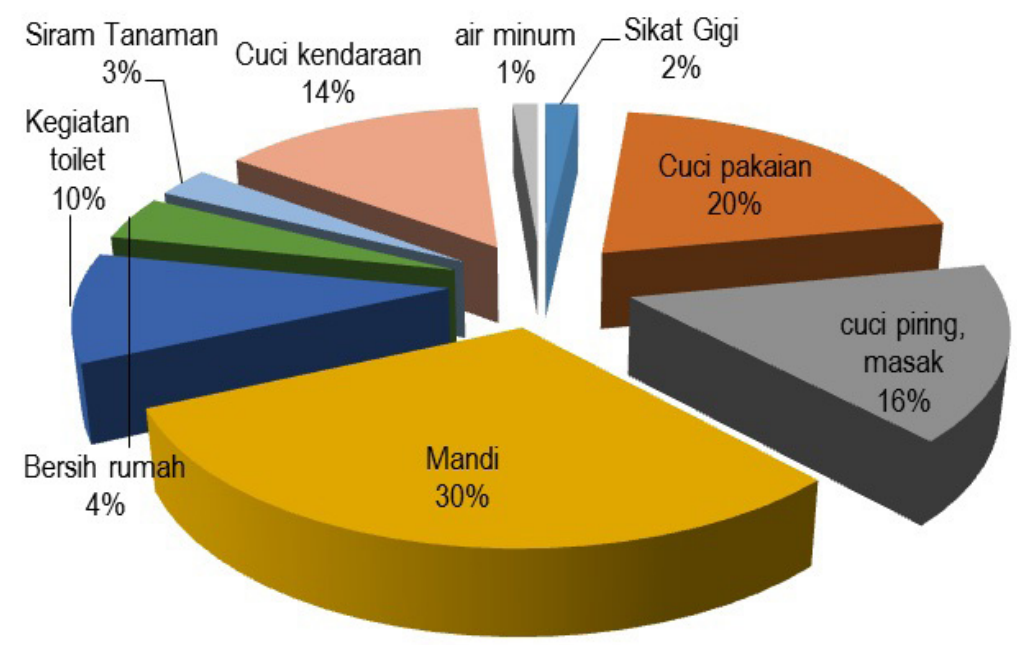

Gambar 3. Grafik pola konsumsi air dalam satu rumah tangga 
Hasil perhitungan total konsumsi air bersih di Perumahan Griya Serpong adalah 524,7 liter/ kepala keluarga. Pemakaian terbanyak untuk kegiatan mandi yaitu $30 \%$ dengan perkiraan jumlah air sebanyak 157,41 Liter untuk mandi. Perkiraan jumlah anggota keluarga sekitar 4 orang. Rata rata responden menjawab dalam sehari mandi 2 kali sehari. Peralatan mandi responden kebanyakan menggunakan gayung dan volume gayung sekali digunakan dapat mencapai 1 liter, dengan demikian volume air mandi menggunakan gayung akan lebih banyak. Penggunaan shower akan mengurangi pemakaian air untuk mandi sehingga dapat menghemat pemakaian air.

Tabel 6. Standar kebutuhan air Departemen Pekerjaan Umum

\begin{tabular}{cc}
\hline Keperluan & Konsumsi (L) \\
\hline Mandi, cuci, kakus & 12,0 \\
Minum & 2,0 \\
Cuci pakaian & 10,7 \\
Kebersihan rumah & 31,4 \\
Taman & 11,8 \\
Cuci kendaraan & 21,1 \\
wudhu & 16,2 \\
Lain-lain & 21,7 \\
Jumlah & 126,9 \\
\hline
\end{tabular}

Sumber (Departemen PU, 1994)

Perumahan Griya Serpong mempunyai jumlah kepala keluarga sebanyak 375 KK, berdasarkan hasil penelitian kebutuhan air bersih tiap kepala keluarga sebanyak 524,7 liter, maka kebutuhan air bersih di perumahan Griya Serpong adalah 196.762,5 liter per hari.

\section{SIMPULAN}

Penduduk perumahan Griya Serpong tergolong pengguna efektif air bersih sebesar 135,7 liter/ jiwa/hari jika dibandingkan dengan standar pemakaian air pada jenis kota Metropolitan sebesar 150 liter/jiwa/hari. Dengan pola konsumsi air bersih sebesar 30\% digunakan untuk mandi, 20\% untuk cuci pakaian, $16 \%$ untuk kegiatan dapur, 14\% untuk cuci kendaraan, 10\% untuk kegiatan toilet dan sisanya untuk menunjang aktifitas harian lainnya. Hasil penelitian prosentase terbesar penggunaan air untuk mandi dan kebiasaan menggunakan gayung sebagai alat untuk mandi; maka perlu untuk dibuat pilihan lain untuk menggantikan gayung sebagai alat mandi.

\section{UCAPAN TERIMA KASIH}

Penulis mengucapkan terimakasih kepada tim pelaksana dan pembina kegiatan RPPI-12 Puslitbang Kualitas dan Laboratorium Lingkungan (P3KLL) Serpong.

\section{DAFTAR PUSTAKA}

(1) Rencana Strategis KLHK 2015-2019, Kementerian Lingkungan Hidup dan Kehutanan, 2015

(2) Konferensi APRSCP ke-10 tahun http://www.menlh.go.id/konferensike-10-asia-pacific-roundtablefor-sustainable-consumption-andproduction-aprscp//

(3) Said N I, Daur ulang air limbah (water recycle) ditinjau dari aspek teknologi, lingkungan dan ekonomi, BPPT, JAI Vol 2, No.2 tahun 2006

(4) Madonna S, Efisiensi energy melalui penghematan penggunaan air, Universitas Bakrie, Jakarta, Jurnal Teknik Sipil Volume 12 No. 4 April 2014: 267-274. 
(5) Santoso A, Karnaningrum N, dkk, Perencanaan Pengolahan Air Limbah Domestik Dengan Alternatif media biofilter (studi kasus: kejawan gebang kelurahan keputih surabaya), prosiding seminar nasional manajemen teknologi XXII, program studi MMT-ITS, Surabaya 24 Januari 2015

(6) Soewondo, Yulianto A, The effect of aeration mode on submerged aerobic bio filter Reactor for grey water treatment, journal of applied sciences in environmental sanitation, Volume 3, Number 3: 169-175, SeptemberDecember, 2008

(7) Survei Kebutuhan air, Direktorat Pengembangan Air Minum, Ditjen Cipta Karya pada 2006 http:// ciptakarya.pu.go.id/v3/news . php?id=101, unduh 06122016, jam 18.05

(8) Said N I, Teknologi pengolahan air limbah Dengan proses biofilm tercelup, Jurnal Teknologi Lingkungan, Vol.1, No. 2, Januari 2000

(9) Kota Tangerang Selatan Dalam Angka Tangerang Selatan in Figures 2013, Badan Pusat Statistik Kota Tangerang Selatan, 2013

(10) Pengambilan Contoh Uji Air dan Air limbah, Standar Nasional Indonesia, SNI. 6989. 59.2008, Badan Standarisasi Nasional (BSN) Tahun 2008

(11) Jufrisal, Zakir M, Perancangan prototype kran wudhu otomatis berbasis Arduino Uno untuk menghemat air menggunakan sensor ping, Seminar Nasional Teknologi Informasi, komunikasi dan Industri (SNTIKI) Pekanbaru, 11 November 2015
(12) Pedoman Konstruksi dan Bangunan, Dep. PU dalam Direktorat Pengairan dan Irigasi Bappenas. 2006

(13) Peraturan menteri lingkungan hidup dan kehutanan Republik indonesia Nomor: p.68/menlhk/setjen/ kum.1/8/2016 Tentang Baku mutu air limbah domestik, tahun 2016

(14)Fardiaz S, Polusi air dan udara, Bogor : Kanisius; 1992

(15) Efendi H, Telaah Kualitas air bagi pengelolaan sumber daya dan lingkungan perairan, Bogor : Kanisius ;2003

(16) Marlina, L, Pencemar Air: sumber, dampak dan penanggulangannya, pengantar ke falsafah sains (PPS702), IPB, June 2004

(17) Alternatif Media Biofilter (Studi Kasus: Kejawan Gebang Kelurahan Keputih Surabaya)

(18) Herlambang A, Pencemaran Air dan Strategi Penanggulangannya, JAI Vol 2, N0. 1 tahun 2006

(19) Chen, H. (2015). Using Water Footprints for Examining the Sustainable Development of Science Parks, 5521-5541. http://doi. org/10.3390/su7055521

(20) Handayani, D. S, Handayani, Kajian Pustka Potensi Pemanfaatan Grey Water sebagai Air Siram WC dan Siram Tanaman di Rumah Tangga, jurnal Presipitasi Vol 10 No. 1 Maret 2013, ISSN 1907-187X

(21) Sosiawan, H dan Subagyo, K, Strategi Pembagian Air Secara proporsional Untuk Keberlanjutan Pemanfaatan Air, Pengembangan inovasi Pertanian 2 (4), 2009: 299-305

(22) Widayat Wahyu, Daur Ulang Air Limbah Domestik Kapasitas 0,9 M3 per Jam Menggunakan Kombinasi Reaktor Biofilter Anaerob Aerob dan Pengolahan Lanjutan, JAI Vol 5. No. 12009 